\title{
The differences in the relationship between diastolic dysfunction, selected biomarkers and collagen turn-over in heart failure patients with preserved and reduced ejection fraction
}

\author{
Błażej Michalski ${ }^{1}$, Przemysław Trzciński ${ }^{1}$, Karolina Kupczyńska ${ }^{1}$, Dawid Miśkowiec ${ }^{1}$, \\ Łukasz Pęczek ${ }^{2}$, Barbara Nawrot ${ }^{2}$, Piotr Lipiec ${ }^{1}$, Jarosław D. Kasprzak ${ }^{1}$ \\ ${ }^{1}$ Department of Cardiology, Medical University of Lodz, Poland \\ ${ }^{2}$ Centre of Molecular and Macromolecular Studies of the Polish Academy of Sciences, \\ Department of Bioorganic Chemistry, Lodz, Poland
}

\begin{abstract}
Background: The aim of the study was to assess the correlation of the selected biomarkers and collagen turn-over indices with advanced echocardiographic parameters among patients with preserved and reduced ejection fraction $(E F)$.

Methods: We included 62 patients with the symptomatic heart failure. The patients were divided in to two groups according to the evaluated ejection fraction ( $E F$ - Simpson method): heart failure with reduced ejection fraction $(H F r E F)$ group - 30 patients with low $E F-35-50 \%$ (16 male, mean age $54.9 \pm 12.6$ ), heart failure with preserved ejection fraction $(H F D E F)$ group - 32 patients with $E F$ $>50 \%$ (16 male, mean age $62.3 \pm 7.6$ ). Clinical evaluation included 6-min walk test, biochemistry, procollagen type I N-terminal propeptide (PINP), procollagen type III N-terminal propetide (PIIINP), matrix metaloproteinase-2 (MMP2), ghrelin, and galectin-3 levels measurements. Echocardiographic examination was performed with analysis of diastolic function and global longitudinal strain (GLS). Results: The GLS in the HFrEF group was significantly lower than in the HFpEF group at the baseline (GLS: 9.56 vs. 16.03, $p<0.01$ ). There was a strong negative correlation of the PIIINP and GLS in $H F r E F$ group $(r=-0.74, p=0.005)$, but only a moderate negative correlation in HFpEF $(r=-0.55$, $p=0.02)$. In the HFrEF group, there was a moderate negative correlation between the baseline level of galectin-3 and GLS ( $r=-0.59, p=0.03)$. The correlation of ghrelin and tissue inhibitor of matrix metalloproteinase-1 with EF in the HFrEF group was moderate and statistically significant $(r=0.62$, $p=0.02$ and $r=-0.63, p=0.02$, respectively).

Conclusions: Procollagen type III peptide has a strong negative correlation with left ventricular GLS. Galectin-3 relationship with strain may indicate novel pathophysiological pathways and requires further investigation. (Cardiol J 2017; 24, 1: 35-42)
\end{abstract}

Key words: diastolic dysfunction, heart failure, adipokines

\section{Introduction}

More than $50 \%$ of patients with heart failure symptoms present with normal ejection fraction (HFpEF) [1]. Myocardial fibrosis and diastolic dys- function are considered landmarks of the developed HFpEF. The major risk factors are age, diabetes, and hypertension. In clinical practice, echocardiography is the first-line diagnostic method, however accurate diagnosis of $\mathrm{HFpEF}$ remains a challenge,

Address for correspondence: Błażej Michalski, MD, Department of Cardiology, Medical University of Lodz, Bieganski Hospital, ul. Kniaziewcza 1/5, 91-347 Łódź, Poland, tel: +48 501681795, fax: +48 422516015, e-mail: bwmichalski@op.pl 
as mitral flow Doppler alone has $40-70 \%$ specificity in reliable detection of diastolic dysfunction $[2,3]$. Tissue Doppler imaging (TDI), including the left ventricular (LV) filling index and transmitral flow velocity to annular velocity ratio (E/E'), are useful for the determination of LV filling pressure [4]. The LV filling index $\mathrm{E} / \mathrm{E}^{\prime}$ is a clinically accepted marker but has limitations in characterization of diastolic dysfunction [5]. Strain and strain rate by speckle tracking are angle-independent methods validated for the evaluation of cardiac function [6]. Longitudinal myocardial shortening assessment contributes to the overall assessment of myocardial function and diastolic dysfunction, although it is not superior to already established TDI analysis including $\mathrm{E} / \mathrm{E}^{\prime}$ in patients with only mild degree of disease [7].

Myocardial histological changes, including extracellular collagen deposition, strongly influence LV systolic and diastolic properties. In patients with hypertension, accumulation of collagen I and III was increased. Animal studies of LV hypertrophy indicate that despite the preserved ejection fraction (EF), the amount of collagen accompanied by abnormal diastolic stiffness is present [8]. In patients with ischemic heart disease, hormonal and immune activation affects the progression of LV dysfunction and heart failure (HF) [9]. Elevated serum levels of collagen III reflect myocardial remodeling, which is associated with significant LV dilatation and persistently depressed LVEF [10]. In this study, we investigated the correlation of the collagen turnover biomarkers and selected adipokines with markers of myocardial function evaluated by echocardiography in patients with heart failure with reduced or preserved ejection fraction (HFrEF; HFpEF). We chose adiponectin, leptin, galectin-3, and ghrelin due to recently published data which suggest their important role in diastolic dysfunction [11-13]. Leptin is an adipokine which attenuates the LV hypertrophy and improves diastolic function of the heart [14]. Adiponectin may play an important role in protection against cardiac remodeling by attenuating myocardial hypertrophy [15]. Galectin receptors have been detected in macrophages in dysfunctional hearts and galectin-3 was suggested to correlate with echocardiographic indices of diastolic function [16]. Ghrelin is a strong stimulant for the release of growth hormone and can reduce peripheral vascular resistance, thus cardiac index and stroke volume index can potentially improve ventricular remodeling [17]. Apelin is an endogenous peptide with many isoforms of which apelin-13 is the most active in the heart. Apelin-13 induces vasodilation which leads to a reduction in mean filling pressure, resulting in a decrease of preload and afterload [18]. The purpose of this study was to establish the relationship of selected adipokines and collagen turnover products with diastolic dysfunction among patients with preserved and reduced ejection fraction.

\section{Methods}

We enrolled 62 patients from our outpatient clinic with HF symptoms. They were divided into two groups according to the EF: group I $\mathrm{HFrEFF}$ with $\mathrm{EF}<50 \%$ and $\mathrm{EF}>35 \%$, group II - patients with $\mathrm{HFpEF}$ and $\mathrm{EF}>50 \%$. All patients had exercise dyspnea or exercise intolerance, captured by abnormal 6 -min walk test and elevated $\mathrm{N}$-terminal-pro-B type natriuretic peptide (NT-proBNP) plasma levels. Patients with HFrEF had a history of ST elevation myocardial infarction treated with primary coronary angioplasty of the single vessel at least 6 months but no more than 24 months before the inclusion into the study. Patients with $\mathrm{HFpEF}$ were included according to the recent European Society of Cardiology guidelines and they presented symptoms of the HF, LVEF $\geq 50 \%$, elevated NT-proBNP, and enlargement of the left atrium (LAE) or LV hypertrophy [19]. Patients with acute or decompensated HF were excluded. Atrial fibrillation, significant valvular or coronary artery disease, as obtained by angiography or computed tomography of the coronary arteries, and lung diseases, as obtained by X-ray and functional test, resulted in patient exclusion. Patients with tissue fibrosis disease, such as chronic liver disease, pulmonary fibrosis, or rheumatoid arthritis were excluded, because these conditions are associated with increased collagen turnover biomarkers. At the baseline, the laboratory evaluation included blood level of C-reactive protein, NT-proBNP, adiponectin, ghrelin, leptin, fasting glucose, lipid profile, 6-min walk test and echocardiographic examination with the TDI and strain analysis. Each patient included into the study had signed the informed consent. The study was approved by the local Ethics Committee.

\section{Echocardiography}

All patients underwent echocardiographic examination performed on VIVID $9(2.5 \mathrm{MHz}$ probe, GE Ultrasound). The standard parasternal and apical views to evaluate the heart chamber's dimensions, valve function, $\mathrm{EF}$ and diastolic function (E/A) were obtained [20]. For speckle tracking, according to the technical requirements, a high 
temporal resolution of the recorded cine-loop 2-dimensional images (in grayscale) was set to achieve at least 60 frames per second (FPS) or more. The speckle tracking echocardiography analysis included the manual contouring of the LV endocardium and the approval of the proper level of the imaging quality of the analyzed area. The LV strain was calculated offline using a dedicated workstation with software enabling speckle tracking (EchoPac version 12.1.0, GE Healthcare). The average value of peak systolic longitudinal strain and peak systolic strain rate from all three apical views was then calculated as global strain $\left(\mathrm{SI}_{\mathrm{SYS}}\right)$ and global strain rate $\left(\mathrm{SR}_{\mathrm{SYS}}\right)$, respectively [4]. Similarly, peak global strain rate during early $\left(\mathrm{S}_{\mathrm{RE}}\right)$ and late $\left(\mathrm{S}_{\mathrm{RL}}\right)$ diastole and during isovolumetric relaxation $\left(\mathrm{SR}_{\mathrm{IVR}}\right)$ was determined. Diastolic indices $\mathrm{E} / \mathrm{SR}_{\mathrm{E}}$ and $\mathrm{E} / \mathrm{SR}_{\mathrm{IVR}}$ were calculated [7]. During TDI, a $1.5 \mathrm{~mm}$ sample volume was placed at the leaflet origin of the mitral annulus. Early (E') diastolic peak velocities of $\mathrm{LV}$ longitudinal fibers were measured at the lateral and septal mitral annulus from apical 4 chamber view with $1.5 \mathrm{~mm}$ sample volume of the pulsed wave tissue Doppler.

\section{Laboratory tests}

Blood samples for specified biomarkers were collected on the day of echocardiographic examination at 8:00 a.m. after at least $14 \mathrm{~h}$ of fasting. The citrated plasma and serum were stored at $-70^{\circ} \mathrm{C}$ until assaying. All markers were measured by an enzyme-linked immunosorbent assay (ELISA) leptin and adiponectin (BioVendor - Laboratorni medicina a.s., Brno, Czech Republic), procollagen I carboxyterminal propeptide (PICP), matrix metallopeptidase 2 (MMP2), tissue inhibitor of matrix metalloproteinase-1 (TIMP-1), procollagen type I $\mathrm{N}$-terminal propeptide (PINP), galectin-3 (GAL-3), collagen type I-telopeptide (CTXI), apelin 13, ghrelin, and procollagen type III N-terminal propeptide (PIIINP) (Cloud-Clone Corp., Houston, TX, USA) in the laboratory of the Department of Bioorganic Chemistry of Center of Molecular and Macromolecular Studies of the Polish Academy of Science in Lodz, Poland. Serum concentrations of sodium, potassium, creatinine, creatine kinase isoenzyme $\mathrm{MB}$ mass (CK-MB), troponin $\mathrm{C}$, and lipids were assessed in all patients.

\section{Statistical analysis}

The analyses were performed using the Statistica 8.0 (StatSoft Polska, Krakow, Poland) software. The normality of the distribution was tested with the Shapiro-Wilk's test. The analysis of variance was performed using Levene's test and the BrownForsythe test. Student's t-test for independent variables and the Mann-Whitney U pairwise comparison for independent variables were used as appropriate. The correlation coefficients were calculated according to Spearman's or Pearson's method. Values of $\mathrm{p}<0.05$ were considered statistically significant. All presented data are expressed as means and standard deviations or medians and quartiles.

\section{Results}

\section{Patient characteristics}

Baseline characteristics of the included patients are summarized in Table 1 . The average age in the HFrEF group (35\% < EF < 50\%) was $54.9 \pm 12.6$ years and in the HFpEF group (EF $>50 \%)$ it was $62.3 \pm 7.6$ years. Patients with HFpEF showed a significantly lower level of NT-proBNP $(211.86 \pm 68.5 \mathrm{pg} / \mathrm{mL}$ vs. $738.2 \pm 1,105.4$ $\mathrm{pg} / \mathrm{mL}, \mathrm{p}<0.05)$. Moreover, diabetes mellitus was more frequent among patients with HFpEF. In addition, in $\mathrm{HFrEF}$ and HFpEF groups, frequency of therapy with an angiotensin-converting enzyme inhibitor or angiotensin-receptor blocker $(90 \%$ vs. $94 \%$ ), diuretic use (60\% vs. $31 \%$ ) and beta-blockers (97\% vs. $94 \%)$ was high.

\section{Echocardiography}

Heart volumes, as well as flow and tissue Doppler measurements are listed in Table 2. LVEF was lower in the HFrEF than in the HFpEF group ( $38.6 \%$ vs. $59.5 \%, p<0.05$ ); also global longitudinal strain at aortic valve closure $\left(\mathrm{GLS}_{\mathrm{AvC}}\right)$ was lower in patients with HFrEF (-9.56 vs. -16.03 , $\mathrm{p}<0.05)$. In patients with HFrEF the LV end diastolic volume was larger than in HFpEF (122.3 vs. $93 \pm 22.2, \mathrm{p}<0.05)$ and the LV mass index was increased. Patients from $\mathrm{HFrEF}$ had the increased E'/A E/E' and decreased $\mathrm{SR}_{\mathrm{IVR}}, \mathrm{SR}_{\mathrm{E}}, \mathrm{SR}_{\mathrm{L}}$.

\section{The levels of biomarkers}

Ghrelin and leptin concentrations were statistically significantly lower in the group with HFrEF, in contrast to the elevated level of PICP (Table 3). The correlation of ghrelin and TIMP1 with EF in the HFrEF group was moderate and statistically significant $(r=0.62, p=0.02$ and $r=-0.63, p=0.02$, respectively). In the $\mathrm{HFpEF}$ group, there was a moderate correlation of $\mathrm{EF}$ and PIIINP $(\mathrm{r}=-0.56$, $\mathrm{p}=0.01)$. In the HFpEF group, there was statistically significant correlation of the PINP and PICP with $\mathrm{LV}$ end systolic volume $(\mathrm{r}=-0.4, \mathrm{p}=0.02$ 
Table 1. Baseline characteristics of group 1 and group 2.

\begin{tabular}{|c|c|c|c|}
\hline Clinical characteristic & Group $1-$ HFrEF $(n=30)$ & Group $2-$ HFpEF $(n=32)$ & $\mathbf{P}$ \\
\hline Age & $54.9 \pm 12.6$ & $62.3 \pm 7.6$ & 0.005 \\
\hline Female: & $14(47 \%)$ & $16(47 \%)$ & 0.76 \\
\hline NYHA class & $2.4 \pm 0.6$ & $2.6 \pm 0.3$ & 0.11 \\
\hline \multicolumn{4}{|l|}{ Medical history: } \\
\hline Myocardial infarction & $0(0 \%)$ & $0(0 \%)$ & $>0.05$ \\
\hline Hypertension & $29(97 \%)$ & $31(97 \%)$ & 0.96 \\
\hline Diabetes mellitus & $9(30 \%)$ & $10(31 \%)$ & 0.91 \\
\hline Systolic BP [mm Hg] & $134 \pm 11.9(121-143)$ & $138 \pm 11.8(121-147)$ & 0.55 \\
\hline Diastolic BP [mm Hg] & $79 \pm 9.5(70-83)$ & $85 \pm 8.2(76-89)$ & 0.42 \\
\hline Body mass index & $29.3 \pm 4.8$ & $27.9 \pm 3.7$ & 0.28 \\
\hline 6 min walk test $[\mathrm{m}]$ & $341.2 \pm 48.7$ & $349.32 \pm 62.1$ & 0.49 \\
\hline NT-proBNP [pg/mL] & $738.2 \pm 1105.4$ & $211.86 \pm 68.5$ & 0.01 \\
\hline \multicolumn{4}{|l|}{ Medication: } \\
\hline Beta-blocker & $29(97 \%)$ & $30(94 \%)$ & 0.89 \\
\hline ACEI/ARB & $29(97 \%)$ & $31(97 \%)$ & 0.95 \\
\hline Spironolactone & $27(90 \%)$ & $30(94 \%)$ & 0.58 \\
\hline Thiazides & $18(60 \%)$ & $10(31 \%)$ & 0.02 \\
\hline Oral diabetic drugs & $9(30 \%)$ & $10(31 \%)$ & 0.91 \\
\hline Calcium channel blocker & $0(0 \%)$ & $4(13 \%)$ & 0.04 \\
\hline Digoxin & $7(23 \%)$ & $0(0 \%)$ & 0.01 \\
\hline Statins & $19(63 \%)$ & $21(66 \%)$ & 0.65 \\
\hline
\end{tabular}

$\mathrm{ACEI}$ — angiotensin converting enzyme inhibitor; ARB — angiotensin receptor blocker; BP — blood pressure; HFpEF — heart failure with preserved ejection fraction; HFrEF — heart failure with reduced ejection fraction; NYHA — New York Heart Association; NT-proBNP — $\mathrm{N}$-terminal-pro-B type natriuretic peptide

Table 2. Baseline echocardiographic characteristics of group 1 and group 2.

\begin{tabular}{|c|c|c|c|}
\hline $\begin{array}{l}\text { Echocardiographic } \\
\text { characteristics }\end{array}$ & $\begin{array}{c}\text { Group } 1-\text { HFrEF }(n=30) \\
(35 \%<\operatorname{EF}<50 \%)\end{array}$ & $\begin{array}{c}\text { Group } 2-\text { HFpEF }(n=32) \\
(E F>50 \%)\end{array}$ & $\mathbf{P}$ \\
\hline EDV [mL] & $125 \pm 40.4$ & $93 \pm 22.2$ & $0.0008^{*}$ \\
\hline ESV [mL] & $78 \pm 30.2$ & $32 \pm 9.5$ & $<0.0001^{*}$ \\
\hline LVMI $\left[\mathrm{g} / \mathrm{m}^{2}\right]$ & $173.0 \pm 36.4$ & $137.1 \pm 21.4$ & 0.0004 \\
\hline LVEF [\%] & $38.3 \pm 8.1$ & $59.9 \pm 2.9$ & $<0.0001^{*}$ \\
\hline $\mathrm{E}^{\prime}[\mathrm{cm} / \mathrm{s}]$ & $7.89 \pm 1.8$ & $6.3 \pm 0.9$ & 0.03 \\
\hline E/A ratio & $1.1 \pm 0.56$ & $1.213 \pm 0.42$ & 0.041 \\
\hline $\mathrm{E} / \mathrm{E}^{\prime}$ ratio & $9.4 \pm 6.15$ & $1532 \pm .4 .613$ & $0.007^{*}$ \\
\hline $\mathrm{GLS}_{\mathrm{AVC}}$ & $9.56 \pm 2.3$ & $16.03 \pm 2.9$ & $<0.0001$ \\
\hline $\mathrm{GLS}_{\operatorname{Max}}$ & $10.68 \pm 2.99$ & $16.12 \pm 6.4$ & $<0.0001$ \\
\hline $\mathrm{SR}_{\mathrm{SYS}}$ & $0.56 \pm 0.16$ & $0.8 \pm 0.22$ & $<0.0001$ \\
\hline SRIVR & $0.11 \pm 0.12$ & $0.16 \pm 0.22$ & $0.63^{*}$ \\
\hline
\end{tabular}

*U-Mann-Whitney, all data expressed as medians; HFpEF — heart failure with preserved ejection fraction; HFrEF - heart failure with reduced ejection fraction; EDV — end diastolic volume; ESV - end systolic volume; LVMI — left ventricular mass index; LVEF — left ventricular ejection fraction; $\mathrm{GLS}_{\mathrm{AVC}}-$ global longitudinal strain at aortic valve closure; $\mathrm{GLS}_{\mathrm{Max}}-$ maximal global longitudinal strain; $\mathrm{SR}_{\mathrm{SYS}}-\mathrm{global}_{\mathrm{s}}$ stolic strain rate; $\mathrm{SR}_{\mathrm{IVR}}-$ global strain rate during isovolumetric relaxation

and $\mathrm{r}=-0.38, \mathrm{p}=0.28$, respectively). However, such statistically significant correlation in the group with HFpEF was only observed for LV end diastolic volume and PIIINP $(r=-0.57, \mathrm{p}=0.04)$.
There was a strong negative correlation of the PIIINP and GLS $_{\text {Avc }}$ in the HFrEF group $(r=-0.74$, $\mathrm{p}=0.005$ ), yet only a moderate negative correlation in HFpEF group $(r=-0.55, p=0.02)$. In the 
Table 3. Baseline characteristics of biomarkers in group 1 and group 2.

\begin{tabular}{lccc}
\hline Biomarkers & $\begin{array}{c}\text { Group } \begin{array}{c}1-\text { HFrEF }(\mathbf{n}=30) \\
(35 \%<\text { EF }<50 \%)\end{array} \\
\text { Apelin-13 }[\mathrm{ng} / \mathrm{mL}]\end{array}$ & $\begin{array}{c}\text { Group 2 }- \text { HFpEF }(\mathbf{n}=32) \\
(\text { EF }>50 \%)\end{array}$ & P \\
Adiponectin $[\mu \mathrm{g} / \mathrm{mL}]$ & $2.2 \pm 1.9$ & $1.28 \pm 1.41$ & 0.1 \\
Ghrelin $[\mathrm{pg} / \mathrm{mL}]$ & $8.88 \pm 3.95$ & $8.83 \pm 3.38$ & 0.69 \\
Galectin-3 $[\mathrm{ng} / \mathrm{mL}]$ & $2847 \pm 2776$ & $1464 \pm 1212$ & 0.039 \\
Leptin $[\mathrm{ng} / \mathrm{mL}]$ & $13.53 \pm 8.45$ & $10.71 \pm 4.21$ & 0.51 \\
CTXI $[\mathrm{pg} / \mathrm{mL}]$ & $18.23 \pm 14.1$ & $26.44 \pm 14.29$ & 0.045 \\
PINP $[\mathrm{ng} / \mathrm{mL}]$ & $239 \pm 125.2$ & $232 \pm 94.4$ & 0.88 \\
PICP $[\mathrm{ng} / \mathrm{mL}]$ & $30.77 \pm 27.4$ & $22.21 \pm 14.1$ & 0.63 \\
MMP2 $[\mathrm{ng} / \mathrm{mL}]$ & $154 \pm 112.38$ & $99.21 \pm 45.3$ & 0.01 \\
PIIINP $[\mathrm{ng} / \mathrm{mL}]$ & $15.67 \pm 6.2$ & $15.88 \pm 8.6$ & 0.35 \\
TIMPI $[\mathrm{ng} / \mathrm{mL}]$ & $14.39 \pm 8.41$ & $13.22 \pm 6.17$ & 0.68 \\
\hline
\end{tabular}

U-Mann-Whitney all data expressed as median values; $\mathrm{HFpEF}$ - heart failure with preserved ejection fraction; HFrEF - heart failure with reduced ejection fraction; CTXI — collagen type I-telopeptide; PICP — procollagen I carboxyterminal propeptide; PINP — procollagen type I $\mathrm{N}$-terminal propeptide; PIIINP - procollagen type III N-terminal propeptide; MMP-2 - matrix metallopeptidase 2; TIMP-1 - tissue inhibitor of matrix metalloproteinase-1

Table 4. The correlation of biomarkers with diastolic parameters in patients with HFrEF and HFpEF.

\begin{tabular}{|c|c|c|c|c|c|c|c|c|}
\hline \multirow[t]{2}{*}{ Biomarkers } & \multicolumn{4}{|c|}{ HFrEF $(n=30)$} & \multicolumn{4}{|c|}{ HFpEF $(n=35)$} \\
\hline & $E / A$ & $E / E^{\prime}$ & E & A & $E / A$ & $E / E^{\prime}$ & E & A \\
\hline Apelin & NS & $\begin{array}{c}r=-0.56 \\
p=0.03\end{array}$ & NS & NS & NS & NS & NS & NS \\
\hline Adiponectin & NS & NS & NS & NS & NS & $\begin{array}{l}r=0.45 \\
p=0.01\end{array}$ & $\begin{array}{l}r=0.64 \\
p=0.02\end{array}$ & NS \\
\hline Galectin 3 & NS & $\begin{array}{l}r=0.64 \\
p=0.03\end{array}$ & $\begin{array}{l}r=0.69 \\
p=0.04\end{array}$ & NS & NS & NS & NS & NS \\
\hline Ghrelin & NS & $\begin{array}{c}r=-0.72 \\
p=0.01\end{array}$ & NS & NS & NS & NS & NS & NS \\
\hline Leptin & NS & NS & NS & NS & NS & NS & NS & NS \\
\hline CTXI & NS & NS & NS & NS & NS & NS & NS & NS \\
\hline PICP & $\begin{array}{l}r=0.62 \\
p=0.02\end{array}$ & NS & NS & $\begin{array}{c}r=-0.61 \\
p=0.01\end{array}$ & NS & NS & NS & NS \\
\hline PINP & NS & NS & NS & NS & NS & NS & NS & NS \\
\hline PIIINP & NS & NS & NS & NS & $\begin{array}{c}r=-0.46 \\
p=0.03\end{array}$ & NS & NS & NS \\
\hline MMP-2 & NS & NS & NS & NS & NS & $\begin{array}{l}r=0.45 \\
p=0.03\end{array}$ & $\begin{array}{l}r=0.52 \\
p=0.03\end{array}$ & NS \\
\hline
\end{tabular}

HFpEF — heart failure with preserved ejection fraction; HFrEF — heart failure with reduced ejection fraction; CTXI — collagen type I-telopeptide; PICP — procollagen I carboxyterminal propeptide; PINP — procollagen type I N-terminal propeptide; PIIINP — procollagen type III $\mathrm{N}$-terminal propeptide; MMP-2 - matrix metallopeptidase 2

HFrEF group, there was a moderate negative correlation between the levels of GAL-3 and GLS $_{\mathrm{AvC}}$ $(\mathrm{r}=-0.59, \mathrm{p}=0.03)$.

In the group with $\mathrm{HFrEF}$, there was a statistically significant correlation of the PICP with the $\mathrm{E} / \mathrm{A}$ values $(\mathrm{r}=0.62, \mathrm{p}=0.02)$ and GAL-3 with $\mathrm{E} / \mathrm{E}^{\prime}(\mathrm{r}=0.64, \mathrm{p}=0.03)$ (Table 4). However, in this group, we can observe an inverse correlation of apelin and ghrelin with the E/E' $(\mathrm{r}=-0.56$, $\mathrm{p}=0.03$ and $\mathrm{r}=-0.72, \mathrm{p}=0.01$, respectively) (Table 4). According to the flow Doppler measurements in patients with $\mathrm{HFpEF}$, we observed the correlation of PIIINP with E/A and adiponectin with $\mathrm{E}(\mathrm{r}=0.46, \mathrm{p}=0.03$ and $\mathrm{r}=0.64 \mathrm{p}=0.02$, 
respectively). The TDI data in the HFpEF group showed the correlation of adiponectin and MMP-2 with $\mathrm{E} / \mathrm{E}^{\prime}(\mathrm{r}=0.45, \mathrm{p}=0.013$ and $\mathrm{r}=0.45$, $\mathrm{p}=0.03$, respectively).

\section{Discussion}

The key finding of our study was an evidence of a relationship between the different levels of selected biomarkers and echocardiographic parameters among patients with $\mathrm{HFpEF}$ or HFrEF. The early diastolic velocity of the mitral valve annulus (E') reflects the rate of myocardial relaxation and the $\mathrm{E} / \mathrm{E}^{\prime}$ ratio is more sensitive than the $\mathrm{E} / \mathrm{A}$ ratio for identifying $\mathrm{LV}$ diastolic dysfunction [21]. Unlike other Doppler parameters of diastolic function, E' velocity appears to be relatively independent from preload, especially when the rate of myocardial relaxation is decreased [21]. In addition, the ratio of early transmitral flow velocity $(\mathrm{E})$ to early diastolic septal mitral annulus velocity (E/E') has been recently shown to be the most accurate noninvasive predictor of elevated LV filling pressure [21].

The levels of apelin and galectin were higher in the HFrEF group. It was previously confirmed on an animal model that the level of apelin is higher in $\mathrm{HF}$ and it leads to an increase in contractility of the heart muscle without pressure overload [22]. The increased level of PCIP and PINP among patients with HFrEF suggests a correlation with myocardial fibrosis and diastolic dysfunction. Increased collagen level in this group indicates an early remodeling process that causes an increase in the ventricular stiffness resulting in diastolic dysfunction. There was also a strong inverse correlation in the HFrEF group of ghrelin with apelin and positive of GAL-3 with $\mathrm{E} / \mathrm{E}$ '. The inverse correlation of apelin with $\mathrm{E} / \mathrm{E}$ ' and its protective activity was also confirmed on a murine animal model where administration of apelin resulted in reduced $\mathrm{LV}$ preload and afterload, and increased contractile reserve without evidence of hypertrophy [22]. Additionally, apelin prevents tissue growth factor-beta from inducing both, the expression of myofibroblast marker alpha-smooth muscle actin and collagen production [23].

Adiponectin also plays an important role in the LV chamber remodeling and changes in the cardiac structure [24]. It increases the extracellular matrix remodeling by enhancing fibroblast migration and increasing the level of collagen III and total collagen [25]. In our study, only in the group with $\mathrm{HFpEF}$ there was a moderate correlation of adiponectin with $\mathrm{E}$ values $(\mathrm{r}=0.64, \mathrm{p}=0.02)$. It has been previously shown in an animal model that expression of the myocardial adiponectin gene may be decreased in the presence of pressure overload, whereas the serum level of adiponectin may be increased [25].

In patients with $\mathrm{HFpEF}$ the level of ghrelin was significantly lower than in patients with HFrEF. The increased level of ghrelin among the HFrEF patients correlates with previous literature reports [26, 27]. However, there is no data available for the characteristic levels of ghrelin among patients with HFpEF. In the study by Tarek et al. [28], patients with HFpEF had elevated levels of leptin, which opposes ghrelin and may be the reason for the mild elevation of ghrelin. Moreover, among patients with HFrEF, we have observed an inverse correlation between ghrelin and $\mathrm{E} / \mathrm{E}$ ' which is interesting with respect to ghrelin's ability to decrease the production of collagen by fibroblasts [29]. This may be caused by the fact that relaxation induced by ghrelin was decreased by inhibition of prostaglandins release and exacerbated by nitric oxide synthase inhibition [30]. Furthermore, the higher level of ghrelin in patients with HFrEF may have a cardioprotective effect because ghrelin attenuates pressure overload induced by cardiac hypertrophy via a cholinergic anti-inflammatory pathway and decreases deposition of collagen in the heart muscle [31,32].

The correlation of GAL-3 was positive with $\mathrm{E} / \mathrm{E}$ ' and $\mathrm{E}$ value among patients with $\mathrm{HFrEF}$, however such results were not observed for $\mathrm{HFpEF}$ patients. In patients with $\mathrm{HFrEF}$ we also observed the correlation of GAL-3 and $\mathrm{GLS}_{\mathrm{AvC}}$.

Correlations of GAL-3 with fibrosis and PIIINP with impaired filling pressure of the LV were obtained with the use of cardiovascular magnetic resonance (CMR) by Lepojarvi et al. [33]. Moreover, in the study by Lin et al. [34], it was confirmed that the level of galectin correlates with the turnover of biomarkers of extracellular matrix among patients with $\mathrm{HFrEF}$.

In a very big study on a cohort of 600 patients, the level of galectin was shown to be similar in patients with HFpEF and HFrEF, although the increase of galectin levels leads to higher risk of composite end-point (all-cause mortality and HF hospitalization) in patients with HFpEF [35]. However, recent studies have shown that GAL-3 is not a critical modulator of cardiac fibrosis but may delay the hypertrophic response and further studies are needed to clearly establish its role [36]. Interestingly, in patients with HFpEF, there was a statistically significant correlation between adiponectin 
and MMP-2 with the E/E' and an inverse correlation of PIIINP with E/A. Frantz et al. [37] reported similarly elevated TIMP-1 levels in hospitalized $\mathrm{HFpEF}$ and $\mathrm{HFrEF}$ patients. Alterations in MMP, especially in MMP-2, were found to be significant indicators of greater degrees of asymptomatic LV diastolic dysfunction in patients with $\mathrm{HFpEF}$ [38]. The present findings show that myocardial collagen type I synthesis is linked to increased LV stiffening (an inverse correlation with A: $\mathrm{r}=-0.61, \mathrm{p}=0.01$ and positive with $\mathrm{E} / \mathrm{A}: \mathrm{r}=0.62, \mathrm{p}=0.02$ ) but only in HFrEF. This corresponds with the findings by Löfsjögård et al. [39] that biomarkers of collagen type I synthesis and degradation are independently related to LV size and diastolic function in the systolic HF. Furthermore, in our study, we observed an irreversible correlation of PIIINP with $\mathrm{E} / \mathrm{A}(\mathrm{r}=$ $-0.46, \mathrm{p}=0.03)$ and with $\mathrm{GLS}_{\mathrm{AVC}}$ in HFpEF group. In the recently published study PIIINP was confirmed to be the first early biomarker for the HF development in patients with hypertension and normal resting echocardiography [40]. Similar results were confirmed with multi-biomarker approach and the evaluation of the diastolic function by CMR [33].

Among patients with HFrEF, the collagen turnover was higher than in the group with $\mathrm{HFpEF}$ and this may also be a predictor of multiple cardiac events, especially in the elderly [41]. Although the $\mathrm{GLS}_{\mathrm{Avc}}$ values were lower in the group with $\mathrm{HFrEF}$, we have observed the negative correlation with PIIINP levels in both groups.

\section{Conclusions}

These results provide further support for the hypothesis that fibrosis is an important contributor towards the development of $\mathrm{HF}$ and serum markers of collagen turnover and adipokines play an important role in diastolic dysfunction. In patients with HFrEF and HFpEF, the level of apelin, ghrelin, leptin, and PICP varies significantly. There is a moderate correlation of selected adipokines and collagen turnover products with the diastolic dysfunction in patients with $\mathrm{HFrEF}$ and HFpEF. The protective effect of apelin on diastolic dysfunction was observed only in the HFrEF group, however, the negative effect for MMP-2 and adiponectin was present in the HFpEF group. Procollagen type III peptide has a strong negative correlation with LV global longitudinal strain. Galectin-3 and ghrelin relationship with strain may indicate novel pathophysiological pathways and require further investigation.

\section{Acknowledgements}

This paper has been partially financed by the Polish Society of Cardiology [Club 30 Grant Polpharma].

\section{Conflict of interest: None declared}

\section{References}

1. Owan TE, Hodge DO, Herges RM, Jacobsen SJ, Roger VL, Redfield MM. Trends in prevalence and outcome of heart failure with preserved ejection fraction. N Engl J Med, 2006; 355: 251-259.

2. Kasner M, Westermann D, Steendijk P et al. Utility of Doppler echocardiography and tissue Doppler imaging in the estimation of diastolic function in heart failure with normal ejection fraction: A comparative Doppler-conductance catheterization study. Circulation, 2007; 116: 637-647.

3. Kasner M, Gaub R, Westermann D et al. Simultaneous estimation of NT-proBNP on top to mitral flow Doppler echocardiography as an accurate strategy to diagnose diastolic dysfunction in HFPEF. Int J Cardiol, 2011; 149: 23-29. doi: 10.1016/j. ijcard.2009.11.035.

4. Paulus WJ, Tschope C, Sanderson JE et al. How to diagnose diastolic heart failure: a consensus statement on the diagnosis of heart failure with normal left ventricular ejection fraction by the Heart Failure and Echocardiography Associations of the European Society of Cardiology. Eur Heart J, 2007; 28: 2539-2550.

5. Nagueh SF, Appleton CP, Gillebert TC et al. Recommendations for the evaluation of left ventricular diastolic function by echocardiography. Eur J Echocardiogr, 2009; 10: 165-193. doi: 10.1093/ ejechocard/jep007.

6. Abraham TP, Dimaano VL, Liang HY. Role of tissue Doppler and strain echocardiography in current clinical practice. Circulation, 2007; 116: 2597-2609.

7. Kasner M, Gaub R, Sinning D et al. Global strain rate imaging for the estimation of diastolic function in HFPEF compared with pressure-volume loop analysis. Eur J Echocardiogr, 2010; 11: 743-751. doi: 10.1093/ejechocard/jeq060.

8. Narayan S, Janicki JS, Shroff SG, Pick R, Weber KT. Myocardial collagen and mechanics after preventing hypertrophy in hypertensive rats. Am J Hypertens, 1989; 2: 675-682.

9. Zannad F, Alla F, Dousset B, Perez A, Pitt B. Limitation of excessive extracellular matrix turnover may contribute to survival benefit of spironolactone therapy in patients with congestive heart failure: insights from the randomized aldactone evaluation study (RALES). Rales Investigators. Circulation, 2000; 102: 2700-2706.

10. Poulsen SH, Host NB, Jensen SE, Egstrup K. Relationship between serum amino-terminal propeptide of type III procollagen and changes of left ventricular function after acute myocardial infarction. Circulation, 2000; 101: 1527-1532.

11. de Filippi CR, Christenson RH. Evolving role of galectin-3 as a cardiac biomarker: heart failure with preserved ejection fraction and renal function, important pieces of the puzzle. JACC Heart Fail, 2015; 3: 253-256. doi: 10.1016/j.jchf.2014.12.009.

12. Negi SI, Jeong EM, Shukrullah I, Raicu M, Dudley SC Jr. Association of low plasma adiponectin with early diastolic dysfunction. Congest Heart Fail, 2012; 18: 187-191. doi: 10.1111/j.17517133.2011.00276.x.

13. Abd El-Aziz TA, Mohamed RH, Mohamed RH, Pasha HF. Leptin, leptin gene and leptin receptor gene polymorphism in heart failure with preserved ejection fraction. Heart Vessels, 2012; 27 : 271-279. doi: 10.1007/s00380-011-0152-2. 
14. Barouch LA, Berkowitz DE, Harrison RW, O’Donnell CP, Hare JM. Disruption of leptin signaling contributes to cardiac hypertrophy independently body weight in mice. Circulation, 2003; 108: 754-759.

15. Karmazyn M, Purdham DM, Rajapurohitam V, Zeidan A. Signalling mechanisms underlying the metabolic and other effects of adipokines on the heart. Cardiovascular Research, 2008; 79: 279-286. doi: 10.1093/cvr/cvn115.

16. De Boer RA, Lok DJA, Jaarsma T, van der Meer P, Voors AA, Hillege HL, van Veldhuisen DJ. Predictive value of plasma galectin-3 levels in heart failure with reduced and preserved ejection fraction. Ann Med, 2011; 43: 60-68. doi: 10.3109/07853890.2010.538080.

17. Nagaya N, Kojima M, Uematsu M et al. Hemodynamic and hormonal effects of human ghrelin in healthy volunteers. Am J Physiol Regul Integr Comp Physiol, 2001; 280: R1483-R1487.

18. Folino A, Montarolo PG, Samaja M, Rastaldo R. Effects of apelin on the cardiovascular system. Heart Fail Rev, 2015; 20: 505-518. doi: 10.1007/s10741-015-9475-x.

19. Ponikowski P, Voors AA, Anker SD et al. 2016 ESC Guidelines for the diagnosis and treatment of acute and chronic heart failure: The Task Force for the diagnosis and treatment of acute and chronic heart failure of the European Society of Cardiology (ESC) Developed with the special contribution of the Heart Failure Association (HFA) of the ESC. Eur Heart J, 2016; 37: 2129-2200. doi: 10.1093/eurheartj/ehw128.

20. Voigt JU, Pedrizzetti G, Lysyansky P et al. Definitions for a common standard for 2D speckle tracking echocardiography: Consensus document of the EACVI/ASE/Industry Task Force to standardize deformation imaging. J Am Soc Echocardiogr, 2015; 28: 183-193. doi: 10.1016/j.echo.2014.11.003.

21. Ommen SR, Nishimura RA, Appleton CP et al. Clinical utility of Doppler echocardiography and tissue Doppler imaging in the estimation of left ventricular filling pressures: A comparative simultaneous Doppler-catheterization study. Circulation, 2000; 102: 1788-1794.

22. Ashley EA, Powers J, Chen M et al. The endogenous peptide apelin potently improves cardiac contractility and reduces cardiac loading in vivo. Cardiovasc Res, 2005; 65: 73-82. doi: 10.1016/j. cardiores.2004.08.018.

23. Pchejetski D, Foussal C, Alfarano C et al. Apelin prevents cardiac fibroblast activation and collagen production through inhibition of sphingosine kinase 1. Eur Heart J, 2012; 33: 2360-2369. doi: 10.1093/eurheartj/ehr389.

24. O'Shea KM, Chess DJ, Khairallah RJ et al. Effects of adiponectin deficiency on structural and metabolic remodeling in mice subjected to pressure overload. Am J Physiol Heart Circ, 2010; 298: H1639-H16345. doi: 10.1152/ajpheart.00957.2009.

25. Dadson K, Turdi S, Boo S, Hinz B, Sweeney G. Temporal and molecular analyses of cardiac extracellular matrix remodeling following pressure overload in adiponectin deficient mice. PLoS One, 2015; 10: e0121049. doi: 10.1371/journal.pone.0121049.

26. Özcan M, Öztürk GZ, Köse M et al. Evaluation of malnutrition with blood ghrelin and fecal elastase levels in acute decompensated heart failure patients. Turk Kardiyol Dern Ars, 2015; 43: 131-137. doi: 10.5543/tkda.2015.06606.

27. Lund LH, Williams JJ, Freda P, LaManca JJ, LeJemtel TH, Mancini DM. Ghrelin resistance occurs in severe heart failure and resolves after heart transplantation. Eur J Heart Fail, 2009; 11: 789-794.
28. Tarek MA, Amany SK, Noureldin HA. The association of ghrelin-501A/C polymorphism with ghrelin and leptin levels in nonobese Saudi population with type 2 diabetes mellitus. Natl J Physiol Pharm Pharmacol, 2015; 5: 243-249. doi: 10.5455/ njppp.2015.5.1301201530.

29. Ota Y, Kawaguchi Y, Takagi K et al. Ghrelin attenuates collagen production in lesional fibroblasts from patients with systemic sclerosis. Clin Immunol, 2013; 147: 71-78. doi: 10.1016/j. clim.2013.03.001.

30. Soares JB, Rocha-Sousa A, Castro-Chaves P, Henriques-Coelho T, Leite-Moreira AF. Inotropic and lusitropic effects of ghrelin and their modulation by the endocardial endothelium, NO, prostaglandins, GHS-R1a and KCa channels. Peptides, 2006; 27: 1616-1623.

31. Mao Y, Tokudome T, Kishimoto I et al. Endogenous ghrelin attenuates pressure overload-induced cardiac hypertrophy via a cholinergic anti-inflammatory pathway. Hypertension, 2015; 65: 1238-1244. doi: 10.1161/HYPERTENSIONAHA.114.04864.

32. Pei XM, Yung BY, Yip SP et al. Protective effects of desacyl ghrelin on diabetic cardiomyopathy. Acta Diabetol, 2015; 52: 293-306. doi: 10.1007/s00592-014-0637-4.

33. Lepojärvi ES, Pïra OP, Pääkkö E et al. Serum PINP, PIIINP, galectin-3, and ST2 as surrogates of myocardial fibrosis and echocardiographic left ventricular diastolic filling properties. Front Physiol, 2015; 6: 200. doi: 10.3389/fphys.2015.00200.

34. Lin YH, Lin LY, Wu YW et al. The relationship between serum galectin-3 and serum markers of cardiac extracellular matrix turnover in heart failure patients. Clin Chim Acta, 2009; 409: 96-99. doi: 10.1016/j.cca.2009.09.001.

35. de Boer RA, Lok DJ, Jaarsma $\mathrm{T}$ et al. Predictive value of plasma galectin-3 levels in heart failure with reduced and preserved ejection fraction. Ann Med, 2011; 43: 60-68. doi: 10.3109/07853890.2010.538080.

36. Frunza O, Russo I, Saxena A et al. Myocardial galectin-3 expression is associated with remodeling of the pressure-overloaded heart and may delay the hypertrophic response without affecting survival, dysfunction, and cardiac fibrosis. Am J Pathol, 2016; 186: 1114-1127. doi: 10.1016/j.ajpath.2015.12.017.

37. Frantz S, Stork S, Michels K et al. Tissue inhibitor of metalloproteinases levels in patients with chronic heart failure: an independent predictor of mortality. Eur J Heart Fail, 2008; 10: 388-395.

38. Collier P, Watson CJ, Voon V et al. Can emerging biomarkers of myocardial remodelling identify asymptomatic hypertensive patients at risk for diastolic dysfunction and diastolic heart failure? Eur J Heart Fail, 2011; 13: 1087-1095. doi: 10.1093/eurjhf/ hfr079.

39. Löfsjögård J, Kahan T, Díez J et al. Biomarkers of collagen type I metabolism are related to B-type natriuretic peptide, left ventricular size, and diastolic function in heart failure. J Cardiovasc Med (Hagerstown), 2014; 15: 463-469. doi: 10.2459/01. JCM.0000435617.86180.0b.

40. Bielecka-Dabrowa A, Michalska-Kasiczak M et al. Biomarkers and echocardiographic predictors of myocardial dysfunction in patients with hypertension. Sci Rep, 2015; 5: 8916. doi: 10.1038/ srep08916.

41. Barasch E, Gottdiener JS, Aurigemma G et al. The relationship between serum markers of collagen turnover and cardiovascular outcome in the elderly: The Cardiovascular Health Study. Circ Heart Fail, 2011; 4: 733-739. doi: 10.1161/CIRCHEARTFAILURE.111.962027. 